\title{
GLOBAL DEVELOPMENT, TRADE, HUMAN CAPITAL, AND BUSINESS CYCLES
}

\author{
Wei-Bin Zhang \\ Ritsumeikan Asia Pacific University, Japan \\ wbzl@apu.ac.jp
}

\begin{abstract}
This paper generalizes the multi-country growth model with capital accumulation, human capital accumulation, economic structure and international trade by Zhang (2014) by making all the time-independent parameters in Zhang's model as time-dependent parameters. Each national economy consists of one tradable, one non-tradable and one education sector. National economies are different in propensities to save, to obtain education and to consume, and in learning abilities. The model integrates the Solow growth model, the Uzawa two-sector growth model, the Uzawa-Lucas two-sector growth model, and the Oniki-Uzawa trade model within a comprehensive framework. Human capital accumulation is through education in the Uzawa-Lucas model, Arrow's learning by producing, and Zhang's learning by consuming (creative learning). The behavior of the household is described with an alternative approach to household behavior. We simulated the model to demonstrate existence of equilibrium points, motion of the dynamic system, and oscillations due to different exogenous shocks.
\end{abstract}

Keywords: trade pattern, education, non-tradable, economic oscillations, wealth accumulation

JEL classification: F1, F43, F44, J24, J11.

\section{Introduction}

This paper is concerned with identifying economic fluctuation in a synthesized Solow-Uzawa's growth, Oniki-Uzawa trade, and Lucas-Uzawa's two-sector model with exogenous shocks. The model is based on Zhang's model (Zhang, 2014). The main generalization of this study is to treat all the time-independent parameters in Zhang's model as time-dependent. This will make Zhang's original model far more robust as there are many factors, such as technological change, institutional shifts, fashions, seasonal factors, are time-dependent and are considered exogenous. Economics oscillations, often referred as business cycles, are commonly observed in empirical studies. Some researches consider economic oscillations as exogenous. A typical example is agricultural production which is influenced by seasonal changes as well as long-term global climates. Oscillations may also occur in a self-organized economic system without any exogenous influences. There are a lot of theoretical and empirical research about mechanisms and phenomena of economic fluctuations (e.g., Zhang, 1991, 2005, 2006; Lorenz, 1993; Flaschel et al 1997; Chiarella and Flaschel, 2000; Shone, 2002; Gandolfo, 2005; Puu, 2011; Nolte, 2015). These studies show how modern dynamic analysis can be applied to different economic systems, identifying existence of cycles, regular as well as irregular oscillations, and chaos in economic systems. There are also other studies which try to explain economic business cycles from different perspectives. Lucas (1977) demonstrates possible existence of some shocks that affect all sectors in an economy. Chatterjee and Ravikumar (1992) build a neoclassical growth model with seasonal perturbations to taste and technology. They demonstrate how the economic system reacts to seasonal demand and supply perturbations. Gabaix (2011) holds that uncorrelated sectoral shocks are determinants of aggregate fluctuations (see also, Giovanni, 
et al. 2014; Stella, 2015). This study attempts to make a contribution to the literature by identifying economic fluctuations in a trade model with endogenous physical and human capital.

This paper is based on a model recently proposed by Zhang (2014). Zhang's model deals with dynamic interdependence between wealth and physical capital accumulation, human capital accumulation, and trade patterns in a multi-country neoclassical growth theory framework. The basic economic mechanism of wealth accumulation based on the Solow growth model with an alternative approach. International trade follows the trade models with accumulating capital developed by Oniki and Uzawa and others (for instance, Oniki and Uzawa, 1965; Frenkel and Razin, 1987; Sorger, 2002; and Nishimura and Shimomura, 2002). The analytical framework of the Oniki-Uzawa model is important for analyzing interdependence between trade patterns and economic growth. The Oniki-Uzawa model should be extended as it is constructed for the two-country with two goods. In fact, most of trade models with endogenous capital are still either limited to two-country or small open economies without taking account of endogenous human capital. Rather than classifying capital goods and consumer goods as in the Oniki-Uzawa model, we use tradable good and non-tradable. Distinction between tradable good and non-tradable good is significant for explaining many economic issues. There are analytical frameworks with tradable and non-tradable goods for explaining the terms of trade (Mendoza, 1995), for examining exchange rates (Stulz, 1987; Stockman and Dellas, 1989; Backus and Smith, 1993; Rogoff, 2002; Raleva, 2013); for dealing with current account dynamics (Edwards, 1989; Hohberger, et al. 2014), for examining investment structure (Cachanosky, 2014); or for solving the home premium puzzle (Baxter et al., 1998; Pesenti and van Wincoop, 2002). Backus and Smith (1993:1) explains this distinction as follows: "The mechanism is fairly simple. Although the law of one price holds, in the sense that each good sells for a single price in all countries, PPP may not: price indexes combine prices of both traded and nontraded goods, and because the latter are sold in only one country their prices, and hence price indexes, may differ across countries." Stockman and Tesar (1995) observe that the tradable sector is generally more volatile. Zhao et al. (2014) explains the difference between the tradable and non-tradable sectors by introducing labor adjustments in response to impulses. According to Zhao et al. (2014: 230) "Tradable sector variables like capital, investment, consumption and output are more volatile than their nontradable counterparts. This is especially true for output, where the tradable sector is more than two times as volatile. The nontradable sector accounts for almost half of both GDP and total consumption. Understanding the sources of volatility by sector may help in understanding the sources of aggregate fluctuations, the effects of shocks on the aggregate economy, and the likely impact of alternative public policies."

The study treats differences in human capital between countries as endogenous variables. Dynamic interdependence between economic growth and human capital is important for explaining national differences in growth and income (e.g., Easterlin, 1981; Hanushek and Kimko, 2000; Barro, 2001; Krueger and Lindahl, 2001; Galor and Zeira, 1993; Castelló-Climent and Hidalgo-Cabrillana, 2012; Barro and Lee, 2013; and Hanushek et al. 2014). This study considers three sources of learning - education in the Uzawa-Lucas model, Arrow's learning by doing, and Zhang's learning by consuming (which include leisure, family conditions, travels and readings at leisure, and so on). The first formal dynamic growth model with education was proposed by Uzawa (1965). There is an extensive literature on education and economic growth (Mincer, 1974; Tilak, 1989; Could et al., 2001; Tselios, 2008; Fleisher et al. 2011; Zhu, 2011). There is also a large number of the theoretical literature on endogenous knowledge and economic growth (Romer, 1986; Lucas, 1988; Grossman and Helpman, 1991; and Aghion and Howitt, 1998). There are other studies within similar frameworks for addressing different issues related to growth and human capital (e.g., Maoz and Moav, 1999; Galor and Moav, 2004; Fender and Wang, 2003; Erosa et al. 2010). A main 
deviation of our approach from the previous models is that we derive demand of education in an alternative approach to the typical Ramsey approach. It is obviously not only school quality but also family and social environment as well as consumption that should be used to explain the differences in human capital between developed and developing economies. In order to more properly modelling human capital accumulation, this study takes account of Arrow's learning by doing (Arrow, 1962) and Zhang's creative leisure (Zhang, 2013, 2014) in modeling human capital accumulation. This paper is built on Zhang's model (Zhang, 2014). The main generalization of this study is to treat all the time-independent parameters in Zhang's model as time-dependent parameters. The rest of the paper is organized as follows. Section 2 defines the basic model. Section 3 shows how we solve the dynamics and simulates the motion of the global economy. Section 4 carries out comparative dynamic analysis to examine the impact of changes in some parameters on the motion of the global economy. Section 5 concludes the study. The appendix proves the main results in Section 3.

\section{The Model}

The model is a generalization of the trade model proposed by Zhang (2014). The model in this study is developed within the framework of the neoclassical growth theory with international trade. Most neoclassical growth models are based on the pioneering works of Solow (1956). There are many extensions and generalizations of the Solow model (e.g., Burmeister and Dobell, 1970; Azariadis, 1993; Barro and Sala-i-Martin, 1995). This study considers a world economy which consists of multiple countries, indexed by $j=1, \ldots, J$. Country $j$ has population, $\bar{N}_{j}(t), j=1, \ldots, J$. Each country has three sectors: one tradable good sector, one non-tradable goods sector and one education sector. We use an alternative approach to consumer behavior proposed by Zhang (1993). All the national economies can produce a homogenous tradable commodity (Ikeda and Ono, 1992). The commodity is like the commodity in the Solow model which can be consumed and invested. Households own assets of the economy and distribute their incomes to consume, to receive education, and to save. Production sectors or firms use capital and labor. Exchanges take place in perfectly competitive markets. Production sectors sell their product to households or to other sectors and households sell their labor and assets to production sectors. Factor markets work well; factors are inelastically supplied and the available factors are fully utilized at every moment. Saving is undertaken only by households, which implies that all earnings of firms are distributed in the form of payments to factors of production. We omit the possibility of hoarding of output in the form of non-productive inventories held by households. Let price be measured in terms of the tradable good and the price of the good be unit. We denote wage and interest rates by $w_{j}(t)$ and $r_{j}(t)$ respectively, in the $j$ th country. Capital depreciates at an exponential rate $\delta_{j k}(t)$ in country $j$. Let $p_{j}(t)$ and $p_{j s}(t)$ denote the price of education and the price of non-tradable good in country $j$. We use subscript index, $i, s$ and $e$ to stand for tradable good sector, non-tradable good sector, and education sector, respectively, in country $j$. We use $N_{j m}(t)$ and $K_{j m}(t)$ to stand for the labor force and capital stocks employed by sector $m$ in country $j$. Let $F_{j m}(t)$ stand for the output level of sector $m$ in country $j$.

\section{The labor supply}

The aggregated labor force $N_{j}(t)$ of country $j$ is given by

$$
N_{j}(t)=H_{j}^{m_{j}(t)}(t) T_{j}(t) \bar{N}_{j}(t),(1)
$$


where $H_{j}(t)$ and $T_{j}(t)$ are respectively the level of human capital and work time in country $j$. Here, $m_{j}(t)$ is a positive parameter measuring how household $j$ effectively applies human capital at time in country $j$.

\section{Marking clearing conditions}

We denote wage rate per unit qualified work time in country $j$ and interest rates by $w_{j}(t)$ and $r_{j}(t)$. In the free trade system, the interest rate is identical throughout the world economy, i.e.,

$$
r(t)=r_{j}(t) \text {. }
$$

We use $K(t)$ to stand for the capital stocks of the world economy. The total capital stock employed by country $j, K_{j}(t)$ is allocated between the tradable, non-tradable and education sectors. We use $\bar{K}_{j}(t)$ to stand for the wealth owned by country $j$. We use $N_{j q}(t)$ and $K_{j q}(t)$ to respectively stand for labor force and capital stocks employed by sector $q$. As full employment of labor and capital is assumed, we have:

$$
K_{j i}(t)+K_{j s}(t)+K_{j e}(t)=K_{j}(t), N_{j i}(t)+N_{j s}(t)+N_{j e}(t)=N_{j}(t) .
$$

We rewrite the above relations as follows:

$$
n_{j i}(t) k_{j i}(t)+n_{j s}(t) k_{j s}(t)+n_{j e}(t) k_{j e}(t)=k_{j}(t), n_{j i}(t)+n_{j s}(t)+n_{j e}(t)=1,
$$

in which

$$
k_{j q}(t) \equiv \frac{K_{j q}(t)}{N_{j q}(t)}, n_{j q}(t) \equiv \frac{N_{j q}(t)}{N_{j}(t)}, k_{j}(t) \equiv \frac{K_{j}(t)}{N_{j}(t)}, q=i, s, e .
$$

\section{Production functions}

We assume that production of sector $(j, q)$ is to combine qualified labor force $N_{j q}(t)$ and physical capital $K_{j q}(t)$. The production function $F_{j q}(t)$ is described by:

$$
F_{j q}(t)=A_{j q}(t) K_{j q}^{\alpha_{j q}(t)}(t) N_{j q}^{\alpha_{j} q(t)}(t), \alpha_{j q}(t), \beta_{j q}(t)>0, \alpha_{j q}(t)+\beta_{j q}(t)=1, j=i, s,(3)
$$

where $A_{j q}(t), \alpha_{j q}(t)$ and $\beta_{j q}(t)$ are positive parameters.

\section{Marginal conditions}

Let all the prices be measured in terms of the good. We use $p_{j s}(t)$ to represent the price of services in country $j$. Markets are competitive; thus labor and capital earn their marginal products, and firms earn zero profits. The rate of interest, wage rate, and prices are determined by markets. Hence, for any individual firm $r(t), w_{j}(t)$ and $p_{j s}(t)$ are given at each point of time. The production sector chooses the two variables $K_{j i}(t)$ and $N_{j i}(t)$ to maximize its profit. The marginal conditions are:

$$
\begin{aligned}
& r(t)+\delta_{j k}(t)=\alpha_{j i}(t) A_{j i}(t) k_{j i}^{-\beta_{j i}(t)}(t), w_{j}(t)=\beta_{j i}(t) A_{j i}(t) k_{j i}^{\alpha_{j i}(t)}(t),(4) \\
& r(t)+\delta_{j k}(t)=\alpha_{j s}(t) A_{j s}(t) p_{j s}(t) k_{j s}^{-\beta_{j s}(t)}(t), w_{j}(t)=\beta_{j s}(t) A_{j s}(t) p_{j s}(t) k_{j s}^{\alpha_{j s}(t)}(t),(5)
\end{aligned}
$$

where $\delta_{j k}(t)$ is depreciation rate of physical capital.

\section{Education sector}

We assume that the education sector is characterized of perfect competition. Students are supposed to pay the education fee $p_{j}(t)$ per unit of time in country. The education sector pays 
teachers and capital with the market rates. The cost of the education sector is given by $w_{j}(t) N_{j e}(t)+\left(r(t)+\delta_{j k}(t)\right) K_{j e}(t)$. The production function of the education sector is assumed to be a function of $K_{j e}(t)$ and $N_{j e}(t)$ as follows:

$F_{j e}(t)=A_{j e}(t) K_{j e}^{\alpha_{j e}(t)}(t) N_{j e}^{\alpha_{j e}(t)}(t), \alpha_{j e}(t), \beta_{j e}(t)>0, \alpha_{j e}(t)+\beta_{j e}(t)=1,(6)$

where $A_{j e}(t), \alpha_{j e}(t)$, and $\beta_{j e}(t)$ are positive parameters. The marginal conditions for the education sector are:

$$
r(t)+\delta_{j k}(t)=\alpha_{j e}(t) A_{j e}(t) p_{j e}(t) k_{j e}^{-\beta_{j e}(t)}(t), w_{j}(t)=\beta_{j e}(t) A_{j e}(t) p_{j e}(t) k_{j e}^{\alpha_{j e}(t)}(t),(7)
$$

\section{Consumer behaviors and wealth dynamics}

This study uses Zhang's utility function to describe behavior of households (Zhang, 1993). Consumers make decisions on distribution of time for work and education, consumption levels of tradable and non-tradable commodities, and saving. Let $\bar{k}_{j}(t)$ stand for wealth of household $j$. Per household's current income from the interest payment $r(t) \bar{k}_{j}(t)$ and the wage payment $H_{j}^{m_{j}(t)}(t) T_{j}(t) w_{j}(t)$ is given by:

$$
y_{j}(t)=r(t) \bar{k}_{j}(t)+H_{j}^{m_{j}(t)}(t) T_{j}(t) w_{j}(t)
$$

We call $y_{j}(t)$ the current income. The total value of wealth that consumers can sell to purchase goods and to save is equal to $\bar{k}_{j}(t)$. Here, we assume that selling and buying wealth can be conducted instantaneously without any transaction cost. The per capita disposable income is then given by:

$$
\hat{y}_{j}(t) \equiv y_{j}(t)+\bar{k}_{j}(t)=(1+r(t)) \bar{k}_{j}(t)+H_{j}^{m_{j}(t)}(t) T_{j}(t) w_{j}(t) .(8)
$$

The disposable income is used for saving, consumption and education. Let $T_{j e}(t)$ stand for the time spent on education. We assume that the total available time is distributed between education and work. The consumer is faced with the following time constraint:

$$
T_{j}(t)+T_{j e}(t)=T_{0},(9)
$$

where $T_{0}$ is the total available time. The consumer is faced with the following budget constraint:

$$
c_{j}(t)+p_{j s}(t) c_{j s}(t)+s_{j}(t)+p_{j}(t) T_{j e}(t)=\hat{y}_{j}(t) \cdot(10)
$$

Insert (9) in (10):

$$
c_{j}(t)+p_{j s}(t) c_{j s}(t)+s_{j}(t)+\bar{p}_{j}(t) T_{j e}(t)=\bar{y}_{j}(t)
$$

Where

$$
\begin{gathered}
\bar{p}_{j}(t) \equiv p_{j}(t)+\bar{w}_{j}(t), \bar{w}_{j}(t) \equiv H_{j}^{m_{j}(t)}(t) w_{j}(t), \\
\bar{y}_{j}(t) \equiv(1+r(t)) \bar{k}_{j}(t)+T_{0} \bar{w}_{j}(t) .(12)
\end{gathered}
$$

Consumers decide four variables, consumption levels of the two goods, level of saving, and education time. We assume that consumers' utility function is a function of the consumption 
level of tradable good $c_{j}(t)$ the consumption level of non-tradable good $c_{j s}(t)$ the education time $T_{j e}(t)$ and the level of saving $s_{j}(t)$ as follows:

$$
U_{j}(t)=c_{j}^{\xi_{j 0}(t)}(t) c_{j s}^{\gamma_{j 0}(t)}(t) s_{j}^{\lambda_{j 0}(t)}(t) T_{j e}^{\eta_{j 0}(t)}(t), \gamma_{j 0}(t), \xi_{0 j}(t), \lambda_{j 0}(t), \eta_{j 0}(t)>0,
$$

where $\xi_{0 j}(t)$ is called the propensity to consume tradable good, $\gamma_{j 0}(t)$ the propensity to consume non-tradable good $\eta_{j 0}(t)$, the propensity to own wealth, and $\lambda_{j 0}(t)$ the propensity to receive education. Maximizing $U_{j}(t)$ subject to the budget constraint yields:

$$
\begin{gathered}
c_{j}(t)=\xi_{j}(t) \bar{y}_{j}(t), p_{j s}(t) c_{j s}(t)=\gamma_{j}(t) \bar{y}_{j}(t), s_{j}(t)=\lambda_{j}(t) \bar{y}_{j}(t), \\
\bar{p}_{j}(t) T_{j e}(t)=\eta_{j}(t) \bar{y}_{j}(t),(13)
\end{gathered}
$$

where

$$
\begin{gathered}
\xi_{j}(t) \equiv \xi_{0 j}(t) \rho_{j}(t), \gamma_{j}(t) \equiv \gamma_{j 0}(t) \rho_{j}(t), \lambda_{j}(t) \equiv \lambda_{j 0}(t) \rho_{j}(t), \eta_{j}(t) \equiv \eta_{j 0}(t) \rho_{j}(t), \\
\rho_{j}(t) \equiv \frac{1}{\xi_{0 j}(t)+\gamma_{j 0}(t)+\lambda_{j 0}(t)+\eta_{j 0}(t)} .
\end{gathered}
$$

In this dynamic system, as any factor is related to all the other factors over time, it is difficult to see how one factor affects any other variable over time in the dynamic system. Our approach to education decision is oversimplified. There are many factors which may affect the decision. For instance, Attanasio and Kaufmann (2014) study the role of expected returns to schooling and of perceived risks (of unemployment and earnings) as determinants of schooling decisions, using Mexican data. They find that expected returns and risk perceptions are play an important role in schooling decisions. Dominitz and Manski (1996) take account subjective expectations of earnings for different schooling degrees. There are also other studies on relations between subjective expectations of earnings and schooling choices in different contexts (Jensen, 2010; Arcidiacono et al. 2012; and Stinebrickner and Stinebrickner, 2012). Although in theory we can take account of these factors by treating the propensities as endogenous variables, for simplicity we consider the propensities fixed in this study.

\section{Wealth accumulation}

According to the definitions of $s_{j}(t)$ the wealth accumulation of the representative household in country $j$ is given by:

$$
\dot{k}_{j}(t)=s_{j}(t)-\bar{k}_{j}(t)-\frac{\dot{N}_{j}(t)}{N_{j}(t)} \bar{k}_{j}(t)
$$

This equation simply states that the change in wealth is equal to the saving minus dissaving.

\section{Human capital accumulation}

According to the study by Hanushek and Woessmann (2008), the cognitive skills of the population, rather than mere school attainment, are strongly related to economic growth, individual earnings, and the distribution. There are many factors which may affect education supply and its quality (e.g., Lazear 2001; Krueger and Whitmore 2001; Bosworth and Caliendo 2007; Maasoumi, et al. 2005; Wossmann and West. 2006). A recent study by Kaarsen (2014) on estimating differences in education quality finds: "there are large differences in education quality across countries. One year of schooling in the U.S. corresponds to 3 or even 4 years of schooling in many developing countries. Moreover, these quality differences are able to account for a considerable share of the variation in income across countries." As human capital is not only affecting by schooling, it is necessary to introduce other possible determinants, such as reading at leisure, available 
information and knowledge outside education institutions, family environment, consumption such as travelling, gaming and parting, as well as social environment outside school, which may paly important role in human capital accumulation. We take account of three sources of improving human capital, through education, "learning by producing", and "learning by leisure". Arrow (1962) first introduced learning by doing into growth theory; Uzawa (1965) took account of trade-offs between investment in education and capital accumulation, and Zhang (2007) introduced impact of consumption on human capital accumulation (via the so-called creative leisure) into growth theory. We propose the following human capital accumulation equation

$$
\begin{aligned}
\dot{H}_{j}(t)= & \frac{v_{j e}(t) F_{j e}^{a_{j e}(t)}(t)\left(H_{j}^{m_{j}(t)}(t) T_{j e}(t) \bar{N}_{j}(t)\right)^{b_{j e}(t)}}{H_{j}^{\pi_{j e}(t)}(t) \bar{N}_{j}(t)}+\frac{v_{j i}(t) F_{j i}^{a_{j i}(t)}(t)}{H_{j}^{\pi_{j i}(t)}(t) \bar{N}_{j}(t)} \\
& +\frac{v_{j h}(t) c_{j}^{a_{j h}(t)}(t)}{H_{j}^{\pi_{j h}(t)}(t)}+\frac{v_{j s}(t) c_{j s}^{a_{j s}(t)}(t)}{H_{j}^{\pi_{j s}(t)}(t)}-\delta_{j h}(t) H_{j}(t),(15)
\end{aligned}
$$

where $\delta_{j h}(t)$ is the depreciation rate of human capital, $v_{j e}(t), v_{j i}(t), v_{j h}(t), a_{j e}(t), b_{j e}(t)$, $a_{j i}(t)$ and $b_{j i}(t)$ are non-negative time-dependent parameters. The signs of the parameters $\pi_{j e}(t), \pi_{j i}(t)$, and $\pi_{j h}(t)$ are not specified as they may be either negative or positive. The equation is a synthesis and generalization of Arrow's, Uzawa's, and Zhang's ideas about human capital accumulation. The term

$$
\frac{v_{j e}(t) F_{j e}^{a_{j e}(t)}(t)\left(H_{j}^{m_{j}(t)}(t) T_{j e}(t) \bar{N}_{j}(t)\right)^{b_{j e}(t)}}{H_{j}^{\pi_{j e}(t)}(t) \bar{N}_{j}(t)}
$$

is the contribution to human capital improvement through education. The term implies that human capital rises in the level of education service $F_{j e}$ and in the (qualified) total study time $H_{j}^{m_{j}} T_{j e} \bar{N}_{j}$. The term $H_{j}^{\pi_{j e}}$ indicates implies that it may be more difficult (in the case of $\pi_{j e}$ being large) or easier (in the case of $\pi_{j e}$ being small) to accumulate more human capital. There are many factors which may affect education quality. For instance, there are studies on relationship between class size and student achievement (Boozer and Rouse 2001; Dobbelsteen et al. 2002; Urquiola, 2006; Bosworth, 2014). The term $v_{j i} F_{j i}^{a_{j i}} / H_{j}^{\pi_{j i}}$ implies learning by producing effects in human capital accumulation.

\section{Market clearing in education markets}

For the education sector, the demand and supply balances in each country:

$$
T_{j e}(t) \bar{N}_{j}(t)=F_{j e}(t) .(16)
$$

\section{Market clearing in non-tradable good markets}

The demand for non-tradable good equals the supply

$$
c_{j s}(t) \bar{N}_{j}(t)=F_{j s}(t) \text {. }
$$

\section{Market clearing in tradable good markets}

The total capital stocks in international markets employed by the production sectors is equal to the total wealth owned by all the countries: 


$$
K(t) \equiv \sum_{j=1}^{J} K_{j}(t)=\sum_{j=1}^{J} \bar{k}_{j}(t) \bar{N}_{j}(t)
$$

The world production is equal to the world consumption and world net savings:

where

$$
C(t)+S(t)-K(t)+\sum_{j=1}^{J} \delta_{k j}(t) K_{j}(t)=K(t)
$$

$$
C(t) \equiv \sum_{j=1}^{J} c_{j}(t) \bar{N}_{j}(t), S(t) \equiv \sum_{j=1}^{J} s_{j}(t) \bar{N}_{j}(t), F(t) \equiv \sum_{j=1}^{J} F_{j i}(t)
$$

\section{International trade}

The trade balances of the economies are given by:

$$
E_{j}(t)=\left(\bar{K}_{j}(t)-K_{j}(t)\right) r(t)
$$

When $E_{j}(t)$ is positive (negative), we say that country $j$ is in trade surplus (deficit). When $E_{j}(t)$ is zero, country $j$ trade is in balance.

We built the model with trade, economic growth, physical and human capital accumulation in the world economy in which the domestic markets of each country are perfectly competitive, international product and capital markets are freely mobile and labor is internationally immobile. The model synthesizes main ideas in economic growth theory and trade theory in a comprehensive framework. The model is general in the sense that some well-known models in economics can be considered as its special cases.

\section{The Dynamics and Equilibrium}

We built a multi-country growth model with have the dynamic equations for the economy with any number of economies. Before examining the dynamic properties of the system, we show that the dynamics of $J$ national economies can be expressed by $2 J$ differential equations. The following lemma is important as it shows how to follow the dynamics of global economic growth with computer.

\section{Lemma}

The motion of $2 J$ variables, $\left\{\bar{k}_{j}(t)\right\}, k_{1 i}(t)$, and $\left(H_{j}(t)\right)$, where $\left\{\bar{k}_{j}(t)\right\}=\left(\bar{k}_{2}(t), \ldots, \bar{k}_{J}(t)\right)$, is given by the following $J$ differential equations:

$$
\begin{gathered}
\dot{k}_{1 i}(t)=\bar{\Lambda}_{1}\left(k_{1 i}(t),\left(H_{j}(t)\right),\left\{\bar{k}_{j}(t)\right\}, t\right), \\
\dot{\bar{k}}_{j}(t)=\bar{\Lambda}_{j}\left(k_{1 i}(t),\left(H_{j}(t)\right),\left\{\bar{k}_{j}(t)\right\}, t\right), j=2, \ldots, J, \\
\dot{\bar{H}}_{j}(t)=\Lambda_{j}\left(k_{1 i}(t),\left(H_{j}(t)\right),\left\{\bar{k}_{j}(t)\right\}, t\right), j=2, \ldots, J,(21)
\end{gathered}
$$

where $\bar{\Lambda}_{j}$ and $\Lambda_{j}$ are functions of $\left\{\bar{k}_{j}(t)\right\}, k_{1 i}(t),\left(H_{j}(t)\right)$, and $t$ defined in the appendix. The values of the other variables are given as functions of $\left\{\bar{k}_{j}(t)\right\}, k_{1 i}(t),\left(H_{j}(t)\right)$, and $t$ at any 
point in time by the following procedure: $k_{j i}(t)$ by $(\mathrm{A} 3) \rightarrow k_{j s}(t)$ by $(\mathrm{A} 1) \rightarrow k_{j e}(t)$ by $(\mathrm{A} 4) \rightarrow$ $r(t)$ and $w_{j}(t)$ by $(4) \rightarrow p_{j}(t)$ by $(\mathrm{A} 5) \rightarrow \bar{k}_{1}(t)$ by $(\mathrm{A} 14) \rightarrow K_{j}(t)$ by $(\mathrm{A} 13) \rightarrow \bar{w}_{j}(t), \bar{p}_{j}(t)$ and $\bar{y}_{j}(t)$ by $(12) \rightarrow \bar{k}_{j}(t)$ by $(\mathrm{A} 12) \rightarrow T_{j}(t)$ by $(\mathrm{A} 11) \rightarrow T_{j e}(t)$ by $(13) \rightarrow N_{j}(t)=$ $H_{j}^{m_{j}(t)}(t) T_{j}(t) \bar{N}_{j}(t) \rightarrow n_{j i}(t)$ and $n_{j s}(t)$ by $(\mathrm{A} 7) \rightarrow n_{j e}(t)$ by $(\mathrm{A} 6) \rightarrow N_{j q}(t)=n_{j q}(t) N_{j}(t)$ $\rightarrow K_{j q}(t)=k_{j q}(t) N_{j q}(t) \rightarrow F_{j i}(t)$ and $F_{j s}(t)$ by $(3) \rightarrow F_{j e}(t)$ by $(6) \rightarrow c_{j}(t)$ and $s_{j}(t)$ by $(13) \rightarrow E_{j}(t)=\left(\bar{K}_{j}(t)-K_{j}(t)\right) \bar{N}_{j}(t)$.

For simulation, we specify values of the parameters. We consider the world consists of three national economies, i.e., $J=3$. We first assume that all the parameters are time-independent. Then we show that the system fluctuates around the paths with the time-independent parameters when some parameter is subject to some time-dependent perturbations. The population and human capital utilization efficiency of the three economies are specified as follows

$$
N_{1}=5, N_{2}=10, N_{3}=20, T_{0}=1, m_{1}=0.9, m_{2}=0.85, m_{3}=0.75 \text {. }
$$

Country 1,2 and 3 's populations are respectively 5,10 and 20 . Country 3 has the largest population. Country 1 uses human capital most effectively and Country 2 next. The parameters in the production functions and physical capital depreciation rates of the three economies are

$$
\begin{gathered}
A_{1 i}=1.3, A_{1 s}=1.2, A_{1 e}=1.1, \alpha_{1 i}=0.32, \alpha_{1 s}=0.35, \alpha_{1 e}=0.45, A_{2 i}=1.25, A_{2 s}=1.1, \\
A_{2 e}=1, \alpha_{2 i}=0.32, \alpha_{2 s}=0.36, \alpha_{2 e}=0.45, A_{3 i}=1.2, A_{3 s}=1, A_{3 e}=0.9, \alpha_{3 i}=0.32, \\
\alpha_{3 s}=0.37, \alpha_{3 e}=0.45, \delta_{1 k}=0.06, \delta_{2 k}=0.05, \delta_{3 k}=0.05 .(23)
\end{gathered}
$$

The total factor productivities are different between three economies. Country 1's total factor productivity is highest and Country 3's total factor productivity is lowest. We call countries 1,2 and 3 respectively as highly developed, developed, and lowly developed economies (HDE, DE, LDE). The output elasticities with respect labor and capital also vary between countries. We specify the values of the parameters, $\alpha_{j}$, in the Cobb-Douglas productions approximately equal to 0.3 . The depreciation rate of physical capital is specified near 0.05 . We specify the household preferences of the three economies as:

$$
\begin{gathered}
\gamma_{10}=0.06, \eta_{10}=0.07, \xi_{10}=0.1, \lambda_{10}=0.73, \gamma_{20}=0.06, \eta_{20}=0.06, \xi_{20}=0.1, \\
\lambda_{20}=0.07, \gamma_{30}=0.06, \eta_{30}=0.05, \xi_{30}=0.1, \lambda_{30}=0.68 .(24)
\end{gathered}
$$

The HDE's propensity to save is 0.73 , the DE's propensity to save is 0.7 , and the LDE's propensity to save is 0.6 . We specify the human capital accumulation as follows:

$$
\begin{gathered}
v_{1 e}=1.2, v_{1 i}=3, v_{1 h}=1.2, v_{1 s}=1.2, a_{1 e}=0.3, b_{1 e}=0.5, a_{1 i}=0.4, a_{1 h}=0.1, \\
a_{1 s}=0.3, \pi_{1 e}=0.1, \pi_{1 i}=0.7, \pi_{1 h}=0.1, \pi_{1 s}=0.1, \delta_{1 h}=0.05, v_{2 e}=1.1, v_{2 i}=2.7, \\
v_{2 h}=1, v_{2 s}=1, a_{2 e}=0.3, b_{2 e}=0.5, a_{2 i}=0.4, a_{2 h}=0.1, a_{2 s}=0.3, \pi_{2 e}=0.1, \\
\pi_{2 i}=0.7, \pi_{2 h}=0.1, \pi_{2 s}=0.1, \delta_{2 h}=0.05, v_{3 e}=1, v_{3 i}=2.5, v_{3 h}=1, v_{3 s}=1, a_{3 e}=0.3, \\
b_{3 e}=0.5, a_{3 i}=0.4, a_{3 h}=0.1, a_{3 s}=0.3, \pi_{3 e}=0.1, \pi_{3 i}=0.7, \pi_{3 h}=0.1, \pi_{3 s}=0.1, \\
\delta_{3 h}=0.05 .(25)
\end{gathered}
$$

The human capital depreciation rates of the three economies are equal. The HDE's human capital accumulation efficiency due to education $v_{1 e}$ is highest, the DE's is next, and the LDE's is lowest. Similarly, the specified values in (24) imply that the HDE is most effective in accumulating human capital, the DE is next, and the LDE is least effective. As we already provided the procedure to follow the motion of each variable in the system, it is straightforward to plot the motion with computer. We specify the initial conditions as follows: 


$$
k_{1 i}(0)=7.4, \bar{k}_{2}(0)=230, \bar{k}_{3}(0)=139, H_{1}(0)=92, H_{2}(0)=84, H_{3}(0)=67 .
$$

It should be noted that this case was already examined by Zhang (2014). We just summarize the simulation results by Zhang. The motion of the system is given in Figure 1. In the figure the GDPs per capita and the global GDP are defined as follows

$$
g_{j} \equiv \frac{F_{j i}+p_{j s} F_{j s}+p_{j e} F_{j e}}{\bar{N}_{j}}, \quad Y \equiv \sum_{j}\left(F_{j i}+p_{j s} F_{j s}+p_{j e} F_{j e}\right) \text {. }
$$

The HDE's GDP per capita and human capital are enhanced over time, the other two countries' GDP per capita and human capital are lowered. The HDE's total labor force and capital stocks employed are augmented and the other two economies' total labor forces and capital stocks employed are lowered. The prices of education and non-tradable goods fall slightly in the three economies. The rate of interest falls and the wage rates are increased. The HDE's wage income per capita is increased, and the other two economies' wage incomes per capita are reduced. The labor and capital are redistributed between the three sectors in each economy over time. The system approaches an equilibrium point in the long term.
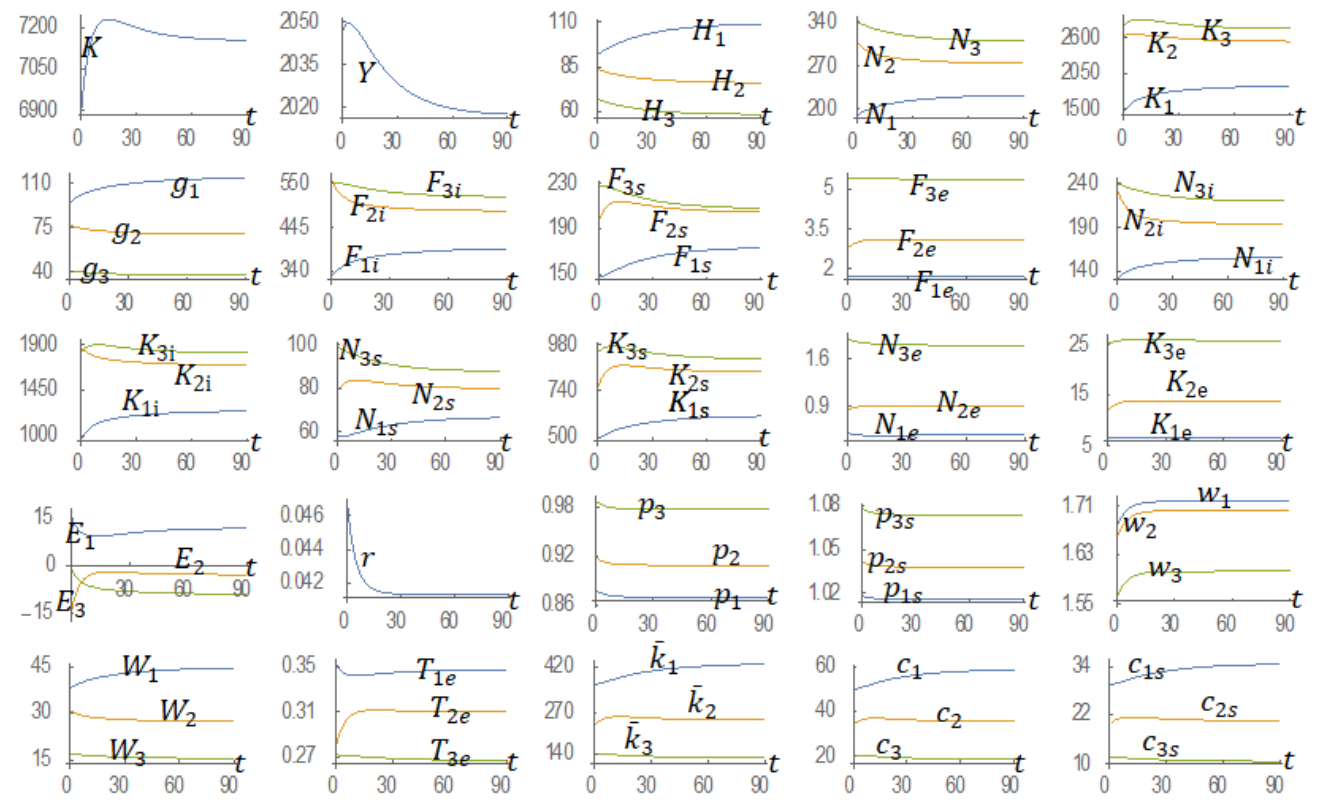

Figure 1: The Motion of the Global Economy

It should be noted that much of the discussion of income convergence in the literature of economic growth and development is based on the insights from analyzing models of closed economies (Barro and Sala-i-Martin, 1995). It is obviously strange to discuss issues related to global income and wealth convergence with a framework without international interactions. The reason for this is that there are few growth models with endogenous wealth and trade on the basis of microeconomic foundation. Figure 1 does not demonstrate that different countries will experience convergence in per capita income, consumption and wealth in the long term. As Barro (2013: 327) observe, "The data reveal a pattern of conditional convergence in the sense that the growth rate of per capita GDP is inversely related to the starting level of per capita GDP, holding fixed measures of government policies and institutions, initial stocks of human capital, and the character of the national population. With respect to education, growth 
is positively related to the starting level of average years of school attainment of adult males at the secondary and higher levels." Our model shows different patterns. We show that the representative household from a country with higher GDP per capita spends more time on education. From Figure 1 we observe that the system becomes stationary in the long term. Following the Lemma under (15), we calculate the equilibrium values of the variables as follows

$$
\begin{gathered}
\left(\begin{array}{l}
r \\
K \\
Y
\end{array}\right)=\left(\begin{array}{l}
0.041 \\
7151 \\
2017
\end{array}\right),\left(\begin{array}{l}
p_{1} \\
p_{2} \\
p_{3}
\end{array}\right)=\left(\begin{array}{l}
0.87 \\
0.91 \\
0.98
\end{array}\right),\left(\begin{array}{l}
p_{1 s} \\
p_{2 s} \\
p_{3 s}
\end{array}\right)=\left(\begin{array}{l}
1.02 \\
1.04 \\
1.07
\end{array}\right),\left(\begin{array}{l}
g_{1} \\
g_{2} \\
g_{3}
\end{array}\right)=\left(\begin{array}{l}
114.6 \\
69.8 \\
37.3
\end{array}\right), \\
\left(\begin{array}{l}
E_{1} \\
E_{2} \\
E_{3}
\end{array}\right)=\left(\begin{array}{l}
11.86 \\
-2.92 \\
-8.95
\end{array}\right),\left(\begin{array}{l}
N_{1} \\
N_{2} \\
N_{3}
\end{array}\right)=\left(\begin{array}{l}
223.6 \\
273.6 \\
308.8
\end{array}\right),\left(\begin{array}{l}
n_{1 e} \\
n_{2 e} \\
n_{3 e}
\end{array}\right)=\left(\begin{array}{l}
0.0022 \\
0.0033 \\
0.0058
\end{array}\right),\left(\begin{array}{l}
n_{1 s} \\
n_{2 s} \\
n_{3 e}
\end{array}\right)=\left(\begin{array}{l}
0.30 \\
0.29 \\
0.28
\end{array}\right), \\
\left(\begin{array}{l}
K_{1} \\
K_{2} \\
K_{3}
\end{array}\right)=\left(\begin{array}{l}
1864 \\
2544 \\
2743
\end{array}\right),\left(\begin{array}{l}
\bar{K}_{1} \\
\bar{K}_{2} \\
\bar{K}_{3}
\end{array}\right)=\left(\begin{array}{l}
2151 \\
2474 \\
2526
\end{array}\right),\left(\begin{array}{l}
k_{1 i} \\
k_{2 i} \\
k_{3 i}
\end{array}\right)=\left(\begin{array}{l}
7.98 \\
8.78 \\
8.27
\end{array}\right),\left(\begin{array}{l}
k_{1 s} \\
k_{2 s} \\
k_{3 s}
\end{array}\right)=\left(\begin{array}{l}
9.13 \\
10.5 \\
10.3
\end{array}\right), \\
\left(\begin{array}{l}
F_{1 i} \\
F_{2 i} \\
F_{3 i}
\end{array}\right)=\left(\begin{array}{l}
395 \\
484 \\
518
\end{array}\right),\left(\begin{array}{l}
F_{1 e} \\
F_{2 e} \\
F_{3 e}
\end{array}\right)=\left(\begin{array}{l}
1.74 \\
3.10 \\
5.34
\end{array}\right),\left(\begin{array}{l}
F_{1 s} \\
F_{2 s} \\
F_{3 s}
\end{array}\right)=\left(\begin{array}{l}
174.1 \\
204.3 \\
207.6
\end{array}\right),\left(\begin{array}{l}
W_{1} \\
W_{2} \\
W_{3}
\end{array}\right)=\left(\begin{array}{l}
44.7 \\
27.4 \\
15.4
\end{array}\right),\left(\begin{array}{l}
34.8 \\
H_{1} \\
H_{2} \\
H_{3}
\end{array}\right)=\left(\begin{array}{l}
109.7 \\
75.9 \\
58.2
\end{array}\right),\left(\begin{array}{l}
T_{1 e} \\
T_{2 e} \\
T_{3 e}
\end{array}\right)=\left(\begin{array}{l}
0.35 \\
0.31 \\
0.27
\end{array}\right),\left(\begin{array}{l}
c_{1} \\
c_{2} \\
c_{3}
\end{array}\right)=\left(\begin{array}{l}
58.9 \\
35.3 \\
18.6
\end{array}\right),\left(\begin{array}{l}
c_{2 s} \\
c_{3 s}
\end{array}\right)=\left(\begin{array}{l}
\bar{k}_{1} \\
\bar{k}_{2} \\
\bar{k}_{3}
\end{array}\right)=\left(\begin{array}{l}
430.3 \\
247.4 \\
126.3
\end{array}\right) .
\end{gathered}
$$

It is straightforward to calculate the six eigenvalues as follows

$$
\{-0.23,-0.22,-0.20,-0.04,-0.04,-0.04\} \text {. }
$$

This implies that the world economy is stable. This implies that we can effectively conduct comparative dynamic analysis.

\section{Comparative Dynamic Analysis}

We simulated the motion of the dynamic system. This section examines effects of changes in some parameters. It is important to ask questions such as how a change in one country's conditions affects the national economy and global economies. First, we introduce a variable $\bar{\Delta} x(t)$ to stand for the change rate of the variable $x(t)$ in percentage due to changes in the parameter value.

\section{Fluctuations in the total factor productivity of the HDE's tradable sector}

First, we study effects of the HDE's technological change in the tradable sector on the global economy. It has been argued that productivity differences explain much of the variation in incomes across countries, and technology plays a key role in determining productivity. We see what will happen to the global economy when the total factor productivity of the HDE's tradable sector experiences the following fluctuations:

$$
A_{1 i}(t)=1.3+0.1 \sin (t) .
$$

The simulation result is plotted in Figure 2. As the system contains many variables and these variables are connected to each other in nonlinear relations, it is difficult to verbally explain 
these interactions over time. As the total factor productivity is fluctuated, the output levels of the three economies' tradable sectors are oscillatory. The output of the HDE's non-tradable sector is oscillatory and the output levels of the other two economies' non-tradable sectors are reduced initially and are slightly affected in the long term. The human capital levels are slightly affected. The FDE's education fee and education time fluctuate, while the other economies' education fees and education times are slightly affected. The trades and rate of interest oscillate. The wealth levels and consumptions do not fluctuate in any economy.
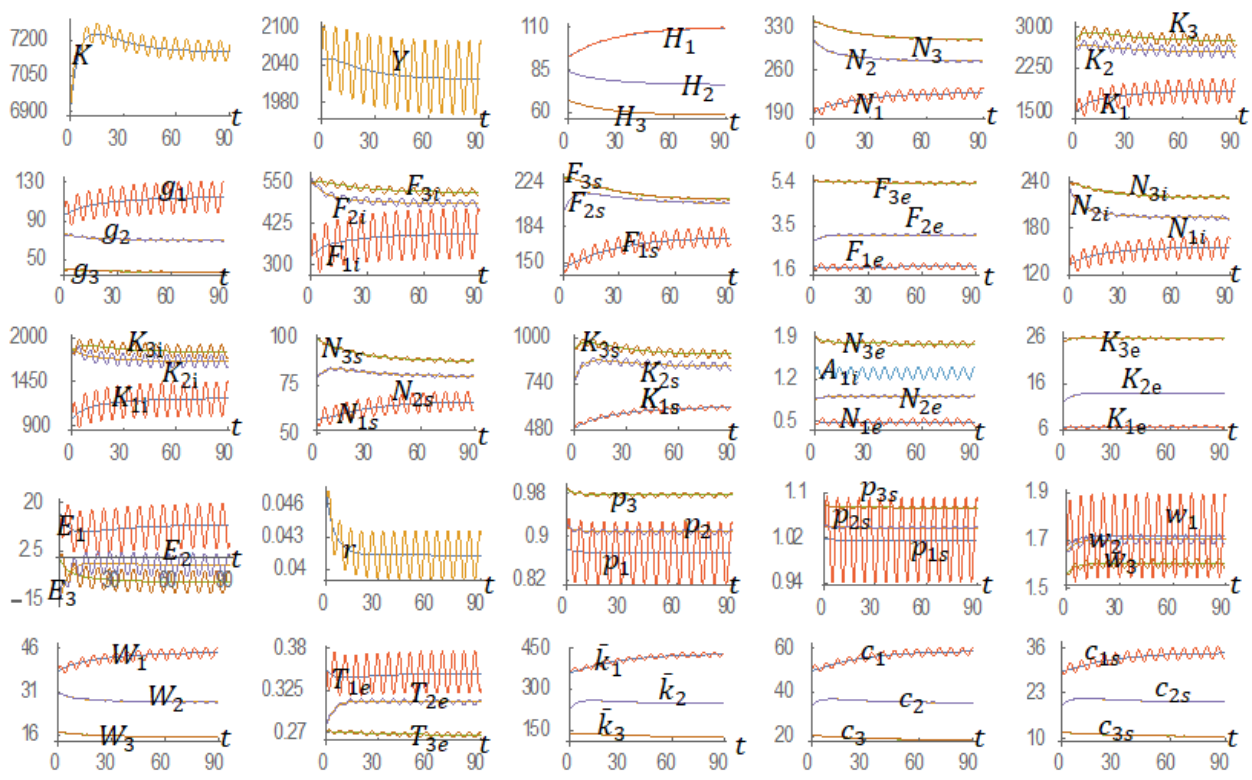

Figure 2: Fluctuations in the Total Factor Productivity of the HDE's Tradable Sector

\section{Fluctuations in the HDE's propensity to receive education}

We now study effects of the following fluctuations in the HDE's propensity to receive education

$$
\eta_{10}(t)=0.07+0.01 \sin (t) \text {. }
$$

The simulation result is plotted in Figure 3. As the representative household's preference to receive education fluctuates, they cause oscillations in the global wealth and global product. The trade patterns are affected periodically. There are also periodic changes in the other variables as shown in Figure 3. 

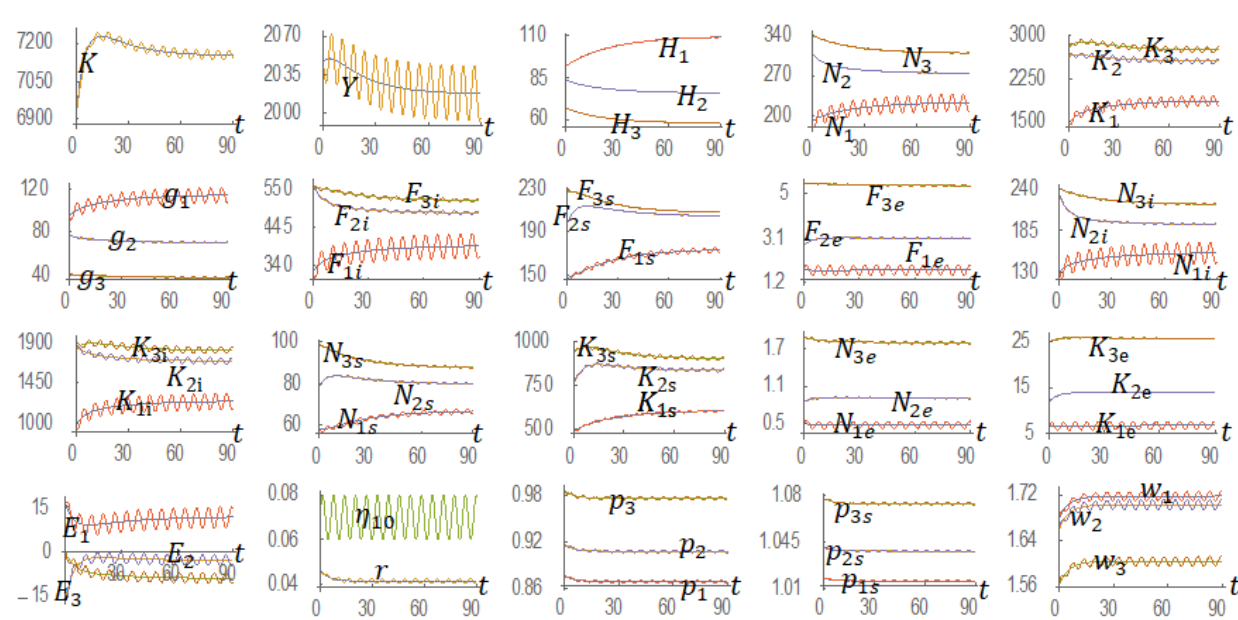

$30 \underbrace{45}_{0} \underbrace{W_{30}}_{30} t$
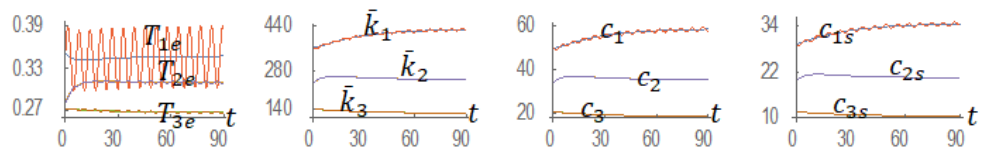

Figure 3: Fluctuations in the HDE's Propensity to Receive Education

\section{Fluctuations in the HDE's efficiency of applying human capital}

We now show effects of the following fluctuations the HDE's human capital utilization efficiency:

$$
m_{1}(t)=0.9+0.05 \sin (t) .
$$

The simulation result is plotted in Figure 4. The parameter changes cause fluctuations in the global wealth and global product. There are slight changes in the human capital levels. The wage rates and rate of interest fluctuate. The output levels of the tradable sectors and trade patterns fluctuate.
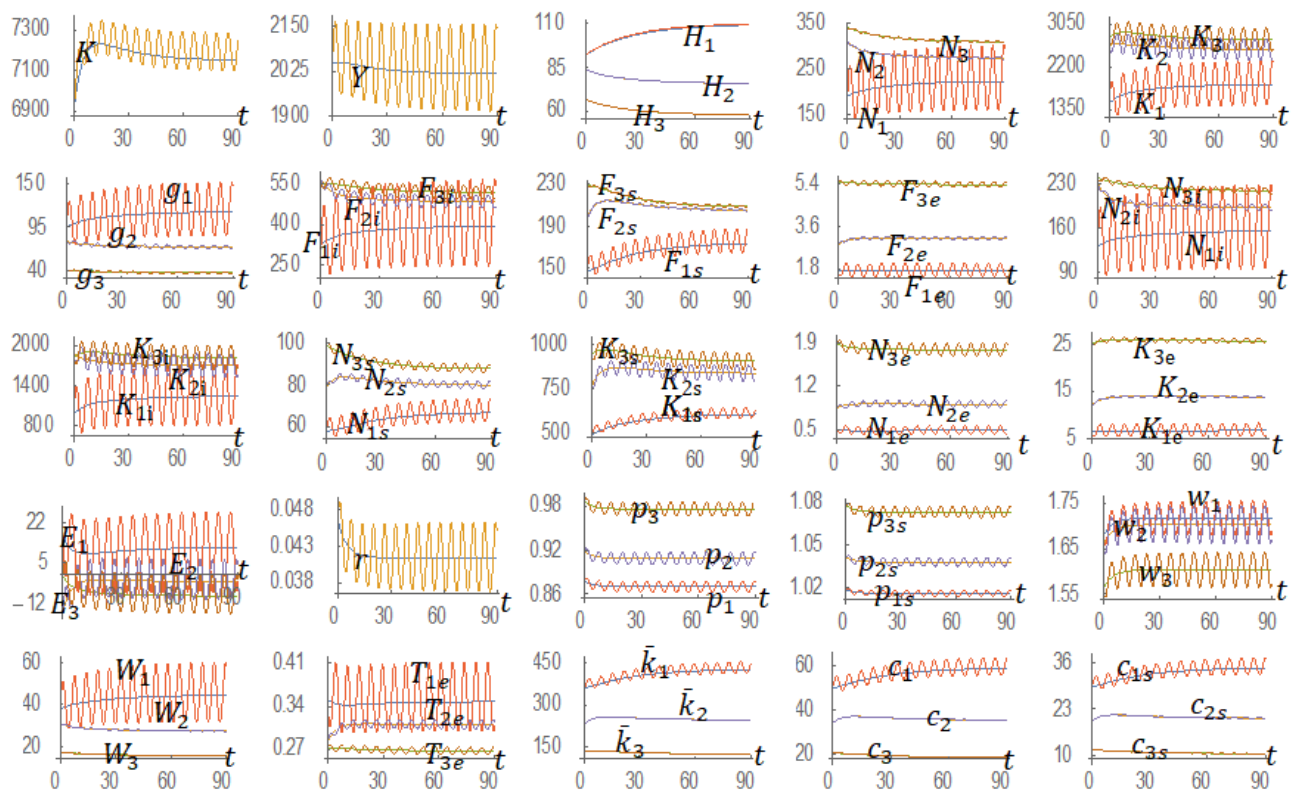

Figure 4: Fluctuations in the HDE's Efficiency of Applying Human Capital 
The LDE's propensity to consume non-tradable goods

We now study what will happen to the global economy when the LDE's propensity to consume the non-tradable good fluctuates as follows:

$$
\gamma_{03}(t)=0.06+0.01 \sin (t)
$$

The simulation result is plotted in Figure 5. As the preference is oscillatory, the global wealth and global output fluctuate. Although there are fluctuations in the economic structure and labor distribution in the LDE, the other two economies are slightly affected.
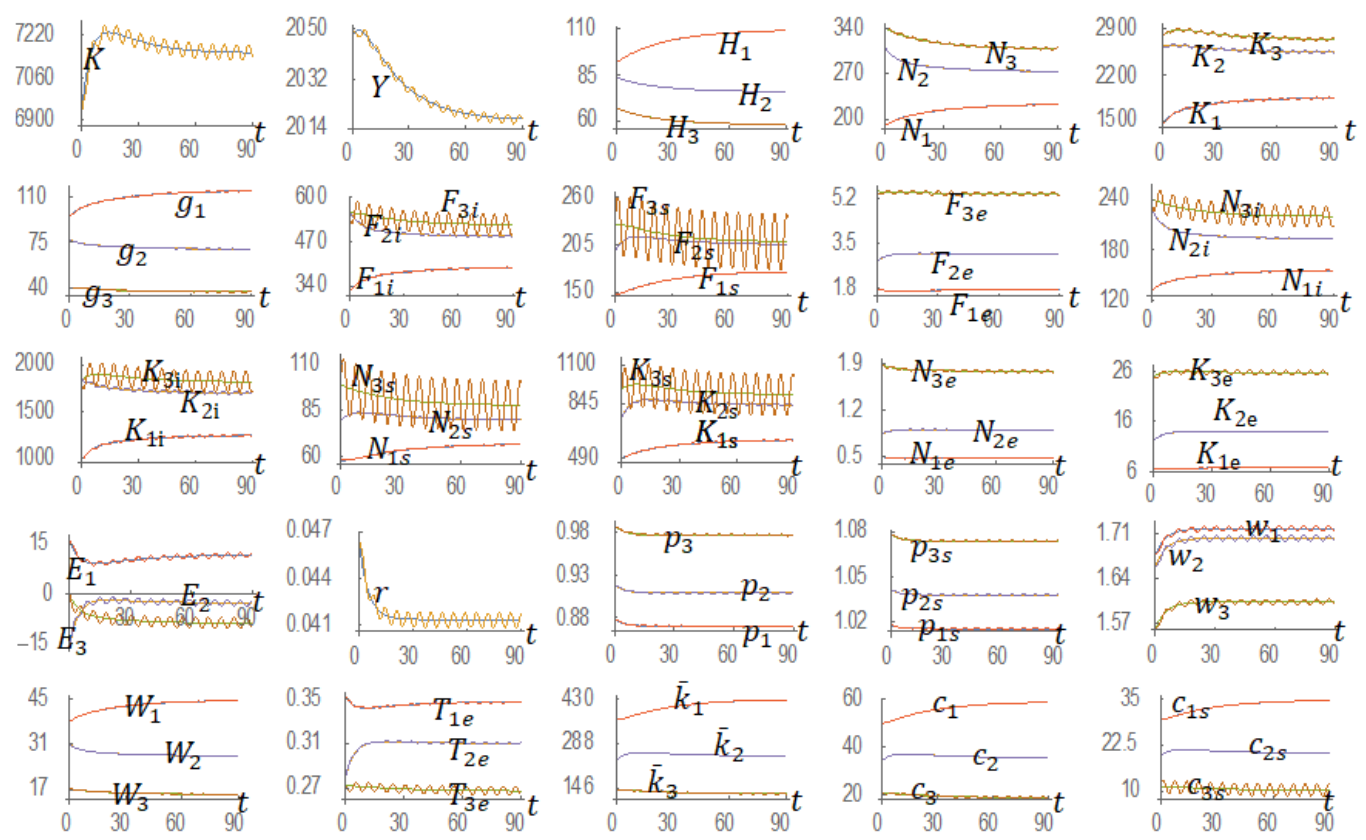

Figure 5: The LDE's Propensity to Consume Non-tradable Goods

\section{Fluctuations in the LDE's propensity to save}

We now allow the LDE's propensity to save to experience the following perturbations:

$$
\lambda_{10}(t)=0.73+0.02 \sin (t) \text {. }
$$

The simulation results are plotted in Figure 6 . We observe that fluctuations in the propensity to save cause weak perturbations in the world economy. A reason is that the effects of saving and dissaving balance each other over time. 

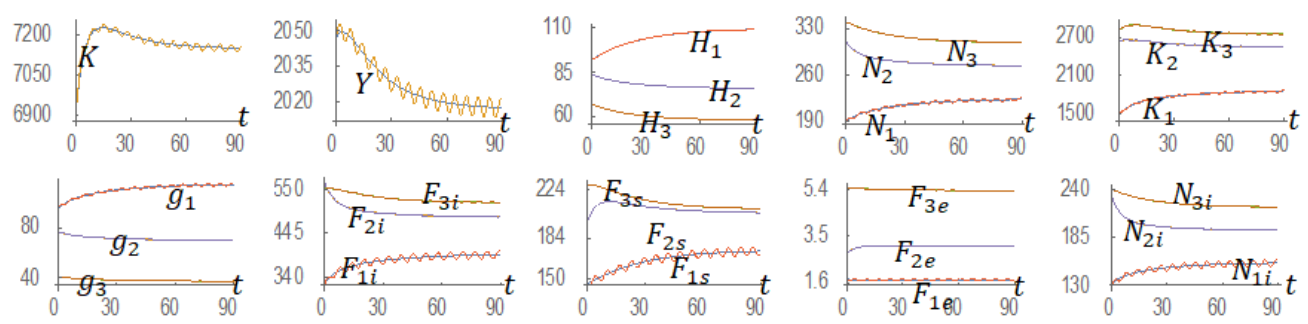

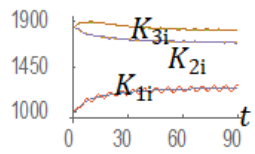
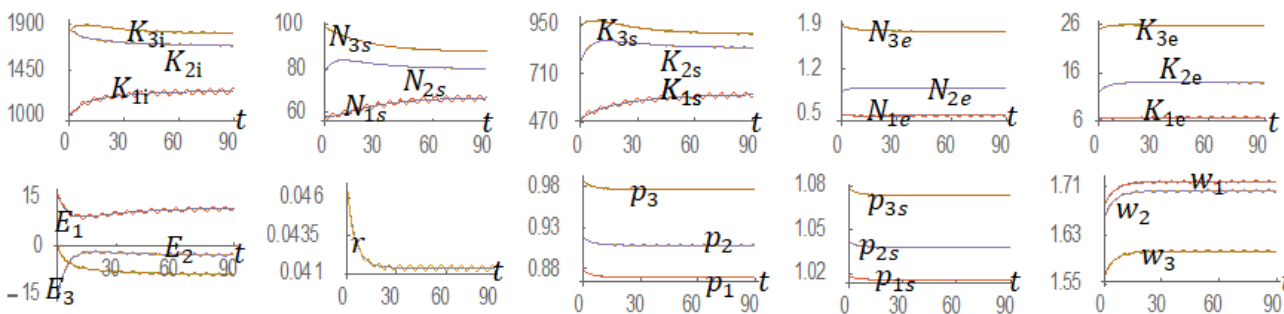

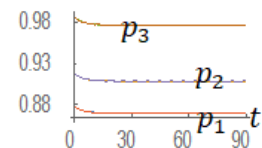
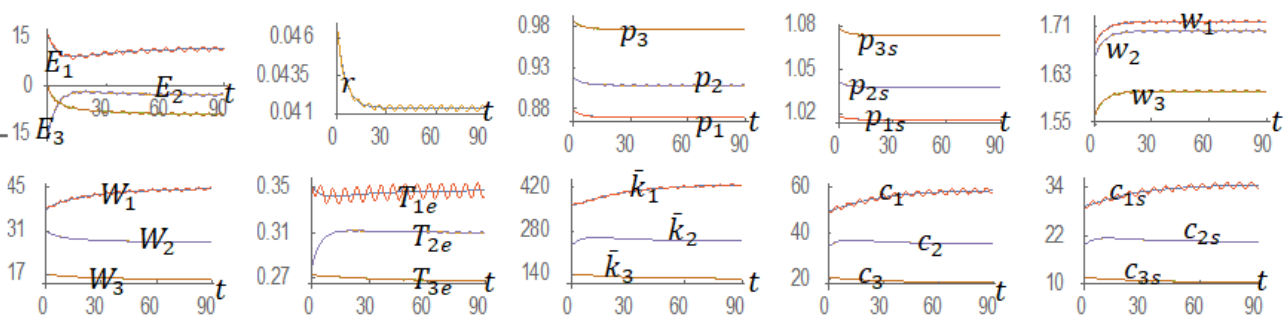

Figure 6: Fluctuations in the LDE's Propensity to Save

\section{Concluding Remarks}

This paper generalized the multi-country growth model with capital accumulation, human capital accumulation, economic structure and international trade by Zhang (2014) by making all the time-independent parameters as time-dependent parameters. Each national economy consists of one tradable, one non-tradable and one education sector. National economies are different in propensities to save, to obtain education and to consume, and in learning abilities. The model integrates the Solow growth model, the Uzawa two-sector growth model, the Uzawa-Lucas two-sector growth model, and the Oniki-Uzawa trade model within a comprehensive framework. Human capital accumulation is through education in the Uzawa-Lucas model, Arrow's learning by producing, and Zhang's learning by consuming (creative learning). The behavior of the household is described with an alternative approach to household behavior. The model describes a dynamic interdependence between wealth accumulation, human capital accumulation, division of labor, and time distribution between education and work under perfect competition. We simulated the model to demonstrate existence of equilibrium points, motion of the dynamic system, and oscillations due to different exogenous shocks. Our model may be extended in different directions. We may introduce some kind of government intervention in education. There are many models which address issues related to taxation, education policy, distribution of income and wealth, and economic growth (e.g., Bénabou, 2002; Glomm and Kaganovich, 2008). The Solow model, the Uzawa two-sector growth, the Oniki-Uzawa trade model, and the Uzawa-Lucas models are most well-known models in the literature of growth theory. The author introduces Zhang's utility and concepts of current income and disposable income indifferent formal economic models (Zhang, 2016a, 2016b, 2018, 2019). Many limitations of our model become apparent in the light of the sophistication of the literature based on these models. 


\section{Appendix: Proving the Lemma}

We check the lemma. We omit time in expressions. From (2), we have: $k_{j i}=\alpha_{0 j} k_{j s},(A 1)$ where

$$
\alpha_{0 j} \equiv \frac{\alpha_{j i} \beta_{j s}}{\alpha_{j s} \beta_{j i}}
$$

From (4) and (5), we determine $p_{j s}$ as a unique function of $k_{j i}$ as follows:

$$
p_{j s}=\frac{A_{j i} \beta_{j i} \alpha_{0 j}^{\alpha_{j s}}}{A_{j s} \beta_{j s}} k_{j i}^{\alpha_{j i}-\alpha_{j s}} .
$$

By (5) and (7) $p_{j}$ are determined as unique functions of $k_{j i}$. From (2), we determine $r$ and $w_{q}$ as unique functions of $k_{j i}$. From (4), we $k_{j i}$ as unique functions of $k_{1 i}$ as follows:

$$
k_{j i}=\left(\frac{A_{j i} \alpha_{j i}}{A_{j i} \alpha_{1 i} k_{j i}^{-\beta_{j i}}-\delta_{1}+\delta_{k}}\right)^{1 / \beta_{j i}}, J=1, \ldots, J .
$$

We have $r, p_{j s}, p_{j}, w_{j}, k_{j s}$ and $k_{j i}$ as unique functions of $k_{1 i}$.

From (4) and (7), we obtain $\quad k_{j e}=\alpha_{j} k_{j i},(A 4)$ where

$$
\alpha_{j} \equiv \frac{\alpha_{j e} \beta_{j i}}{\alpha_{j i} \beta_{j e}}
$$

We also determine $k_{j e}$ as functions of $k_{j i}$. From (A4), (4) and (7), we obtain

$$
p_{j}=\frac{A_{j i} \alpha_{j i} \alpha_{j}^{\beta_{j}}}{A_{j e} \alpha_{j e}} k_{j i}^{\beta_{j}},(A 5)
$$

where $\beta_{j} \equiv \beta_{j e}-\beta_{j i}$. We solve $p_{j}$ as functions of $k_{1 i}$. By (12), we solve $\bar{w}_{j}$ and $\bar{p}_{j}$ as functions of $k_{1 i}$ and $H_{j}$. From (7) and (16), we have:

$$
n_{j e}=\frac{p_{0 j} T_{j e}}{N_{j}} .
$$

where $p_{0 j} \equiv \beta_{j e} p_{j} \bar{N}_{j} / w_{j}$. From (A6) and (2), we solve:

$$
n_{j i} \equiv \frac{\left(k_{j}-k_{j s}\right) N_{j}+\left(k_{j s}-k_{j e}\right) p_{0 j} T_{j e}}{\left(k_{j i}-k_{j s}\right) N_{j}}, n_{j i} \equiv \frac{\left(k_{j i}-k_{j}\right) N_{j}+\left(k_{j e}-k_{j i}\right) p_{0 j} T_{j e}}{\left(k_{j i}-k_{j s}\right) N_{j}} .
$$

From (17) and (13), we have

$$
n_{j s}=\frac{\bar{N}_{j} \beta_{j s} \gamma_{j} \bar{y}_{j}}{w_{j} N_{j}},(\mathrm{~A} 8)
$$

where we also use $w_{j}=\beta_{j s} p_{j s} F_{j s} / N_{j s}$. From (A7) and (A8), we solve:

$$
\left(k_{j i}-k_{j}\right) N_{j}+\left(k_{j e}-k_{j i}\right) p_{0 j} T_{j e}=\frac{\left(k_{j i}-k_{j s}\right) \bar{N}_{j} \beta_{j s} \gamma_{j} \bar{y}_{j}}{w_{j}} .
$$


Insert $N_{j}=H_{j}^{m_{j}} T_{j} \bar{N}_{j}$ and $T_{j e}=\eta_{j} \bar{y}_{j} / \bar{p}_{j}$ in (A9):

where

$$
T_{j}=\frac{\widehat{w}_{j} \bar{y}_{j}}{k_{j i}-k_{j}},(\mathrm{~A} 10)
$$

$$
\widehat{w}_{j}\left(k_{1 i}, H_{j}\right)=\frac{1}{H_{j}^{m_{j}} \bar{N}_{j}}\left[\frac{\left(k_{j i}-k_{j s}\right) \bar{N}_{j} \beta_{j s} \gamma_{j}}{w_{j}}-\frac{\left(k_{j e}-k_{j i}\right) p_{0 j} \eta_{j}}{\bar{p}_{j}}\right] .
$$

From (9) and in (13), we have: $\quad T_{j}=T_{0}-\widetilde{w}_{j} \bar{y}_{j},(A 11)$

where $\widetilde{w}_{j} \equiv \eta_{j} / \bar{p}_{j}$. From (A10) and (A11), we have $k_{j}=k_{j i}-\frac{\widehat{w}_{j} \bar{y}_{j}}{T_{0}-\widetilde{w}_{j} \bar{y}_{j}}$. (A12)

From $K_{j}=k_{j} T_{j} H_{j}^{m_{j}} \bar{N}_{j}$, (A11) and (A12), we have: $K_{j}=h_{j 1} \bar{k}_{j}+h_{j 2},(A 13)$

where we use the definition of $\bar{y}_{j}$ and $\quad h_{j 1} \equiv-(1+r)\left(\widetilde{w}_{j} k_{j i}+\widehat{w}_{j}\right) H_{j}^{m_{j}} \bar{N}_{j}$,

$$
h_{j 2} \equiv T_{0} H_{j}^{m_{j}} \bar{N}_{j} k_{j i}-\left(\widetilde{w}_{j} k_{j i}+\widehat{w}_{j}\right) H_{j}^{m_{j}} \bar{N}_{j} T_{0} \bar{w}_{j} \text {. }
$$

Insert (A13) in (18)

$$
\bar{k}_{1}=\Lambda_{k} \equiv \frac{1}{h_{11}-\bar{N}_{1}}\left(\sum_{j=2}^{J}\left(\bar{N}_{j}-h_{j 1}\right) \bar{k}_{j}-\sum_{j=1}^{J} h_{j 2}\right) .
$$

All the variables can be expressed as functions of $\bar{k}_{1 i},\left(H_{j}\right),\left\{\bar{k}_{j}\right\}$, and $t$ by the procedure in the Lemma. From the procedure in the Lemma and (15), we have:

$$
\dot{H}_{j}=\Lambda_{j}\left(\bar{k}_{1 i},\left(H_{j}\right),\left\{\bar{k}_{j}\right\}, t\right) .(A 15)
$$

Here, we don't provide explicit expressions of the functions as they are tedious. Substituting the definition of $\bar{y}_{j}$ into $s_{j}=\lambda_{j} \bar{y}_{j}$ yields:

$$
s_{j}=(1+r) \lambda_{j} \bar{k}_{j}+\lambda_{j} T_{0} \bar{w}_{j} .(A 16)
$$

Substituting (A16) into (14), we have:

$$
\begin{gathered}
\dot{k}_{1}=\lambda_{1} T_{0} \bar{w}_{1}-R \bar{k}_{1}-\frac{\dot{N}_{1}}{N_{1}} \bar{k}_{1},(A 17) \\
\dot{k}_{j}=\bar{\Lambda}_{j} \equiv \lambda_{j} T_{0} \bar{w}_{j}-\left(1-\lambda_{j}-\lambda_{j} r\right) \bar{k}_{j}-\frac{\dot{N}_{j}}{N_{j}} \bar{k}_{j}, j=2, \ldots J,(A 18)
\end{gathered}
$$

in which $R \equiv 1-\lambda_{1}-\lambda_{1} r$. Taking derivatives of equation (A14) with respect to $t$ yields:

$$
\dot{\bar{k}}_{1}=\frac{\partial \Lambda_{k}}{\partial k_{1 i}} \dot{k}_{1 i}+\sum_{j=1}^{J} \Lambda_{j} \frac{\partial \Lambda_{k}}{\partial H_{j}}+\sum_{j=2}^{J} \bar{\Lambda}_{j} \frac{\partial \Lambda_{k}}{\partial \bar{k}_{j}}+\frac{\partial \Lambda_{k}}{\partial t} \text {. }
$$

where we use (A15) and (A18). Equaling the right-hand sizes of equations (A19) and (A17), we get:

$$
\dot{k}_{1 i}=\bar{\Lambda}_{1} \equiv\left[\lambda_{1} T_{0} \bar{w}_{1}-R \Lambda_{k}-\sum_{j=1}^{J} \Lambda_{j} \frac{\partial \Lambda_{k}}{\partial H_{j}}-\sum_{j=2}^{J} \bar{\Lambda}_{j} \frac{\partial \Lambda_{k}}{\partial \bar{k}_{j}}-\frac{\partial \Lambda_{k}}{\partial t}\right]\left(\frac{\partial \Lambda_{k}}{\partial k_{1 i}}\right)^{-1} .
$$

In summary, we proved the Lemma. 


\section{References}

Aghion, P. and Howitt, P., 1998. Endogenous Growth Theory. Mass., Cambridge: The MIT Press.

Arcidiacono, P., Hotz, V.J., and Kang, S., 2012. Modelling College Major Choices Using Elicited Measures of Expectations and Counterfactuals. Journal of Economics, 166 (1), pp. 316.

Arrow, K.J., 1962. The Economic Implications of Learning by Doing. Review of Economic Studies, 29, pp. 155-73.

Attanasio, O.P. and Kaufmann, K.M., 2014. Education Choices and Returns to Schooling: Mothers' and Youths' Subjective Expectations and Their Role by Gender. Journal of Development Economics, 109, pp. 203-16.

Azariadis, C., 1993. Intertemporal Macroeconomics. Oxford: Blackwell.

Backus, D.K. and Smith, G.W., 1993. Consumption and Real Exchange Rates in Dynamic Economies with Non-Traded Goods. Journal of International Economics, 35, pp. 297-316.

Barro, R.J., 2001. Human Capital and Growth. American Economic Review, Papers and Proceedings 91, pp. 12-17.

Barro, R.J., 2013. Education and Economic Growth. Annals of Economics and Finance, 14 (2), pp. 301-28.

Barro, R.J. and Lee, J.W., 2013. A New Data Set of Educational Attainment in the World, 1950-2010. Journal of Development Economics, 104 (C), pp. 184-98.

Barro, R.J. and Sala-i-Martin, X., 1995. Economic Growth. New York: McGraw-Hill, Inc.

Baxter, M., Jermann, U.J., and King, R.G., 1998. Nontraded Goods, Nontraded Factors, and International Non-Diversification. Journal of International Economics, 44, pp. 211-29.

Bénabou, R., 2002. Tax and Education Policy in a Heterogeneous-Agent Economy: What levels of Redistrbution Maximize Growth and Efficiency? Econometrica, 70, pp. 481-517.

Boozer, M. and Rouse, C., 2001. Intraschool Variation in Class Size: Patterns and Implications. Journal of Urban Economics, 50 (1), pp. 163-89.

Bosworth, R., 2014. Class Size, Class Composition, and the Distribution of Student Achievement. Education Economics, 22, pp. 141-165.

Bosworth, R. and Caliendo, F., 2007. Educational Production and Teacher Preferences. Economics of Education Review, 4, pp. 487-500.

Burmeister, E. and Dobell, A.R., 1970, Mathematical Theories of Economic Growth. London: Collier Macmillan Publishers.

Cachanosky, N., 2014. The Mises-Hayek Business Cycle Theory, Fiat Currencies and Open Economies. The Review of Austrian Economics, 3, pp. 281-99.

Castelló-Climent, A. and Hidalgo-Cabrillana, A., 2012. The Role of Education Quality and Quantity in the Process of Economic Development. Economics of Education Review, 31 (4), pp. 391-409.

Chatterjee, B. S. and Ravikumar, B., 1992. A Neoclassical Model of Seasonal Fluctuations. Journal of Monetary Economics, 29 (1), pp. 59-86.

Chiarella, C. and Flaschel, P., 2000. The Dynamics of Keynesian Monetary Growth: Macro Foundations. Cambridge: Cambridge University Press

Could, E.D., Moav, O., and Weinberg, B.A., 2001. Precautionary Demand for Education, Inequality, and Technological Progress. Journal of Economic Growth, 6, pp. 285-315.

Dobbelsteen, S., Levin, J., and Oosterbeek, H., 2002. The Causal Effect of Class Size on Scholastic Achievement: Distinguishing the Pure Class Size Effect from the Effect of Changes in Class Composition. Oxford Bulletin of Economics and Statistics, 64 (1), pp. 17-38.

Dominitz, J. and Manski, C.F., 1996. Eliciting Student Expectations of the Returns to Schooling. Journal of Human Resources, 31 (1), pp. 1-26. 
Easterlin, R., 1981. Why Isn't the Whole World Developed? Journal of Economic History, 41, pp. 1-19.

Edwards, S., 1989. Temporary Terms of Trade Disturbances, the Real Exchange Rate and the Current Account. Economica, 56, pp. 343-57.

Erosa, A., Koreshkova, T., and Restuccia, D., 2010. How Important Is Human Capital? A Quantitative Theory Assessment of World Income Inequality. The Review of Economic Studies, 77, pp. 1421-49.

Fender, J. and Wang, P., 2003. Educational Policy in a Credit Constrained Economy with Skill Heterogeneity. International Economic Review, 44, pp. 939-64.

Flaschel, P., Franke, R., and Semmler, W. 1997. Dynamic Macroeconomics. Cambridge, Mass: The MIT Press.

Fleisher, B., Hu, Y.F., Li, H.Z., and Kim, S.H., 2011. Economic Transition, Higher Education and Worker Productivity in China. Journal of Development Economics, 94, pp. 86-94.

Frenkel, J.A. and Razin, A., 1987. Fiscal Policy and the World Economy. MA., Cambridge: MIT Press.

Gabaix, X., 2011. The Granular Origins of Aggregate Fluctuations. Econometrica ,79, pp. 733-772.

Galor, O. and Moav, O., 2004. From Physical to Human Capital Accumulation: Inequality in the Process of Development. Review of Economic Studies, 71, pp. 1001-26.

Galor, O. and Zeira, J., 1993. Income Distribution and Macroeconomics. Review of Economic Studies, 60, pp. 35-52.

Gandolfo, G., 2005. Economic Dynamics. Berlin: Springer.

Giovanni, J. Di., Levchenko, A., and Mejean, I., 2014. Firms, Destinations, and Aggregate Fluctuations. Econometrica, 82 (4), pp. 1303-1340.

Glomm, G. and Kaganovich, M., 2008. Social Security, Public Education and the Growth-Inequality Relationship. European Economic Review 52, pp. 1009-1034.

Grossman, G.M. and Helpman, E., 1991. Innovation and Growth in the Global Economy. Cambridge, Mass.: The MIT Press.

Hanushek, E. and Kimko, D., 2000. Schooling, Labor-Force Quality and the Growth of Nations. American Economic Review, 90, pp. 1194-1204.

Hanushek, E.A., Leung, C.K.Y., and Yilmaz, K., 2014. Borrowing Constraints, College Aid, and Intergenerational Mobility. Journal of Human Capital, 8 (1), pp. 1-41.

Hanushek E.A. and Woessmann, L., 2008. The Role of Cognitive Skills in Economic Development. Journal of Economic Literature, 46 (3), pp. 607-668.

Hohberger, S., Vogel, L., and Herz, B., 2014. Budgetary-Neutral Fiscal Policy Rules and External Adjustment. Open Economies Review, 25, pp. 909-936.

Ikeda, S. and Ono, Y., 1992. Macroeconomic Dynamics in a Multi-Country Economy - A Dynamic Optimization Approach. International Economic Review, 33, pp. 629-644.

Jensen, R., 2010. The (Perceived) Returns to Education and the Demand for Schooling. Quarterly Journal of Economics, 125 (2), pp. 515-48.

Kaarsen, N., 2014. Cross-country Differences in the Quality of Schooling. Journal of Development Economics, 107, pp. 215-224.

Krueger, A.B. and Lindahl, M., 2001. Education for Growth: Why and for Whom. Journal of Economic Literature, 39, pp. 1101-1136.

Krueger, A.B. and Whitmore. D.M., 2001. The Effect of Attending a Small Class in the Early Grades on College-Test Taking and Middle School Test Results: Evidence from Project STAR. Economic Journal, 111 (468), pp. 1-28.

Lazear, E.P., 2001. Educational production. Quarterly Journal of Economics 116 (3) 777-803. Lorenz, H.W., 1993. Nonlinear Dynamic Economics and Chaotic Motion. Berlin: Springer-Verlag. 
Lucas, R.E., 1977. Understanding Business Cycles. Carnegie-Rochester Conference Series on Public Policy, 5, pp. 7-29.

Lucas, R.E., 1988. On the Mechanics of Economic Development. Journal of Monetary Economics, 22, pp. 3-42.

Maasoumi, E., Millimet, D.L. and V. Rangaprasad, D.M., 2005. Class Size and Educational Policy: Who Benefits from Smaller Classes? Econometric Reviews, 24 (4), pp. 333-68.

Maoz, Y.D. and Moav, O., 1999. Intergenerational Mobility and the Process of Development. Economic Journal, 109, pp. 677-97.

Mendoza, E.G., 1995. The Terms of Trade, the Real Exchange Rate, and Economic Fluctuations. International Economic Review, 36, pp. 101-137.

Mincer, J., 1974. Schooling, Experience and Earnings. New York: Columbia University Press. Nishimura, K. and Shimomura, K., 2002. Trade and Indeterminacy in a Dynamic General Equilibrium Model. Journal of Economic Theory, 105, pp. 244-260.

Nolte, D.D., 2015. Introduction to Modern Dynamics: Chaos, Networks, Space and Time. London: Oxford University Press

Oniki, H. and Uzawa, H., 1965. Patterns of Trade and Investment in a Dynamic Model of International Trade. Review of Economic Studies, 32, pp. 15-38.

Pesenti, P., van Wincoop, E., 2002. Can Nontradables Generate Substantial Home Bias? Journal of Money, Credit and Banking, 34, pp. 25-50.

Puu, T., 2011. Nonlinear Economic Dynamics. Berlin: Springer.

Raleva, S., 2013. Structural Sources and Characteristics of the Inflation in Bulgaria (1992-2010). Economic Studies, 1, pp. 41-71.

Rogoff, K., 2002. The Purchasing Power Parity Puzzle. Journal of Economic Literature, 34, pp. 647-668.

Romer, P.M., 1986. Increasing Returns and Long-Run Growth. Journal of Political Economy, 94, pp. $1002-1037$.

Shone, R., 2002. Economic Dynamics - Phase Diagrams and Their Economic Application. Cambridge: Cambridge University Press.

Solow, R., 1956. A Contribution to the Theory of Growth. Quarterly Journal of Economics, 70, pp. 65-94.

Sorger, G., 2002. On the Multi-Country Version of the Solow-Swan Model. The Japanese Economic Review, 54, pp. 146-64.

Stella, A., 2015. Firm Dynamics and the Origins of Aggregate Fluctuations. Journal of Economic Dynamics and Control, 55 (C), pp. 71-88.

Stinebrickner, T. and Stinebrickner, R., 2012. Learning about Academic Ability and the College Drop-Out Decision. Journal of Labor Economics, 30 (4), pp. 707-748.

Stockman, A.C. and Dellas, H., 1989. International Portfolio Nondiversification and Exchange Rate Variability. Journal of International Economics, 26, pp. 271-289.

Stockman, A.C. and Tesar, L.L., 1995. Tastes and Technology in a Two-country Model of the Business Cycle: Explaining International Comovements. American Economic Review, 85, pp. 168-185.

Stulz, R. M., 1987. An Equilibrium Model of Exchange Rate Determination and Asset Pricing with Nontraded Goods and Imperfect Information. Journal of Political Economy, 95, pp. 1024-1040.

Tilak, J.B.C., 1989. Education and Its Relation to Economic Growth, Poverty and Income Distribution: Past Evidence and Future Analysis. Washington: World Bank.

Tselios, V., 2008. Income and Educational Inequalities in the Regions of the European Union: Geographically Spillovers under Welfare State Restrictions. Papers in Regional Science, 87, pp. 403-430.

Urquiola, M. and Verhoogen, E., 2009. Class-size Caps, Sorting, and the Regression Discontinuity Design. American Economic Review, 99 (1), pp. 179-215. 
Uzawa, H., 1965. Optimal Technical Change in an Aggregative Model of Economic Growth. International Economic Review, 6, pp. 18-31.

Wossmann, L. and West, M., 2006. Class-size Effects in School Systems around the World: Evidence from Between-Grade Variation in TIMSS. European Economic Review, 50 (3), pp. 695-736.

Zhang, W.B., 1991. Synergetic Economics. Heidelberg: Springer-Verlag.

Zhang, W.B., 1993. Woman's Labor Participation and Economic Growth - Creativity, Knowledge Utilization and Family Preference. Economics Letters, 42, pp. 105-110.

Zhang, W.B., 2005. Differential Equations, Bifurcations, and Chaos in Economics. Singapore: World Scientific.

Zhang, W.B., 2006. Discrete Dynamical Systems, Bifurcations and Chaos in Economics. Amsterdam: Elsevier.

Zhang, W.B., 2007. Economic Growth with Learning by Producing, Learning by Education, and Learning by Consuming. Interdisciplinary Description of Complex Systems, 5, pp. 21-38.

Zhang, W.B., 2013. Income and Wealth Distribution with Physical and Human Capital Accumulation: Extending the Uzawa-Lucas Model to a Heterogeneous Households Economy. Latin American Journal of Economics, 50 (2), pp. 257-287.

Zhang, W.B., 2014. Tradable, Non-tradable and Education Sectors in a Multi-Country Economic Growth Model with Endogenous Wealth and Human Capital. Economic Research Guardian, 4 (2), pp. 65-85.

Zhang, W.B., 2016a. Population Growth and Preference Change in a Generalized Solow Growth Model with Gender Time Distributions. Oradea Journal of Business and Economics, 1 (2), pp. 7-30.

Zhang, W.B., 2016b. Fashion with Snobs and Bandwagoners in a Three-Type Households and Three-Sector Neoclassical Growth Model. The Mexican Journal of Economics and Finance, 11 (2), pp. 1-19.

Zhang, W.B., 2018. A Growth Theory Based on Walrasian General Equilibrium, Solow-Uzawa Growth, and Heckscher-Ohlin Trade Theories. Interdisciplinary Description of Complex Systems - Scientific Journal, 16 (3-B), pp. 452-464.

Zhang, W.B., 2019. Money and Price Dynamics under the Gold Standard in the One-Sector Neoclassical Growth Model. Lecturas de Economía, 90, pp. 45-69.

Zhao, Y., Guo, S., and Liu, X.F., 2014. Trading Frictions and Consumption-output Comovement. Journal of Macroeconomics, 42, pp. 229-240.

Zhu, R., 2011. Individual Heterogeneity in Returns to Education in Urban China during 1995-2002. Economics Letters, 113, pp. 84-87.

\section{Bio-note:}

Zhang Wei-Bin, PhD (Umeå, Sweden), is Professor in APU since 2000. He was graduated in 1982 from Department of Geography, Beijing University. He got Master Degree and completed Ph.D course at Department of Civil Engineering, Kyoto University in 1987. He completed his dissertation on economic growth theory in June, 1989. Since then he researched at the Swedish Institute for Futures Studies in Stockholm for 10 years. His main research fields are nonlinear economic dynamics (synergetic economics), economic theory, ancient Confucianism, and economic development and modernization of Chinese societies. He single-authorized 300 academic articles (210 in international peer-reviewed journals), 22 academic books in English. $\mathrm{He}$ is editorial board members of 14 peer-review international journals. Prof. Zhang is the editor of Encyclopedia of Mathematical Models in Economics (in two volumes) as a part of the unprecedented global effort, The Encyclopedias of Life Support Systems, organized by The UNESCO. 